\title{
Personality Predictors of IT Addiction
}

\author{
Isaac Vaghefi ${ }^{1}$ \\ Binghamton University, State University of New \\ York, NY, USA \\ svaghefi@binghamton.edu
}

\begin{abstract}
Prior research on addiction has extensively looked at the personality traits of individuals and their interactions in explaining various types of substance and non-substance addictions. Recent studies have also shown the importance of neuroticism, conscientiousness, and agreeableness on IT addiction. Nevertheless, little is known in IS research regarding the moderated effects of personality traits on the development of IT addiction. Given the increasing attention to the dark side of IT, in this study, we build on Five-Factor personality model to propose a theoretical model that shows the direct and moderated effects of neuroticism, conscientiousness, and agreeableness on addiction to social networking sites (SNS). We empirically test our research model using data collected from 275 SNS users and covariance-based structural equation modeling technique. Furthermore, we shed light on the moderation effects of these factors on SNS addiction via two post-hoc analyses. The implications for theory and practice are discussed.
\end{abstract}

\section{Introduction}

Research on the "dark side" of information systems (IS) use has been increasing during the last decade with numerous studies showing the negative consequences of maladaptive uses of IS. Defined as users' maladaptive dependency on the IT use that is associated with significant negative consequences on important life activities for the users $[19,33,38,39,42,43]$, IT addiction is among the top concerns for both IS scholars and practitioners [43]. This is due to the ever-growing popularity of hedonic IT artifacts, such as social networking sites (SNS) and smartphone, and their potentially negative consequences especially on performance and productivity. While prior IS research has explained the role and importance of some of the antecedents of addictive behaviors, such as maladaptive habits and perceptions, as important factors in formation

\author{
Hamed Qahri-Saremi ${ }^{1 *}$ \\ DePaul University \\ Chicago, IL, USA \\ hqahrisa@cdm.depaul.edu
}

of IT addiction [33, 39, 41], some other possibly important factors need more attention. One family of such factors is personality traits as potential antecedents of IT addiction, which is the focus of this study.

Prior addiction literature has shown the salient role of personality on addiction. For instance, Miller [27] showed that certain personality types can predict addiction and recovery of alcoholics. Additional comparable studies $[36,48]$ suggest that individuals with certain personality traits may have more predisposition toward developing an addiction. Moreover, prior addiction research has shown that the effect of each personality trait can possibly increase or decrease by other personality traits [37], suggesting a complex interactions among personality traits and their effects on the addiction. Given the ubiquity of IT use in personal life and work environment, it is critical that we understand how personality traits may influence the usage patterns and the development of an addiction to IT and the complexity of interactions among them. Despite their importance, personality traits affecting IT addiction development have received minimal attention in the IS research. In particular, prior IS research has largely overlooked the interaction effects among these factors and how they can influence their effects on It addiction.

The objective of this study is to fulfill this gap and extend the literature on IT addiction by shedding light on key personality traits influencing IT addiction and showing the complexity of interactions among these factors. To this end, we draw on the Five-Factor model (FFM) to develop a research model that investigates the role of neuroticism, conscientiousness, and agreeableness along with their interactions on IT addiction. Our proposed research model was tested using empirical data collected via two surveys from SNS users. Our findings show that while neuroticism has a positive effect on IT addiction, conscientiousness holds a negative effect. Furthermore, we find that the effect of conscientiousness and agreeableness on

\footnotetext{
1. Authors' contributions to this paper are equal.

*. Corresponding Author: Hamed Qahri-Saremi

(hqahrisa@cdm.depaul.edu).
} 
addiction is moderated by neuroticism and conscientiousness, respectively.

These findings contribute to the emerging stream of research on the dark side of IT use by extending our knowledge of the interaction effects among the personality traits and their influence on IT addiction. In this way, they provide a novel view toward better understanding the role of IT users and their personality profiles vis-à-vis IT addiction. The findings will be helpful not just for researchers but also for the practitioners (e.g. managers, policy makers) by providing a more holistic view of the personality types that are more prone to addictive use of hedonic IT, and highlighting that evaluation of a single personality may not be helpful in predicting an addiction; rather, to properly assess the likelihood of developing an IT addiction, they need to assess the personality profile of users and consider the possible interactions among the various traits.

\section{IT Addiction and Personality}

The topic of addiction has been the subject of research for decades. The abundant research on this topic is due to the detrimental consequences that addiction can impose on individuals suffering from this behavioral problem. In common term, addiction is "a repetitive habit pattern that increases the risk of disease and/or associated with personal and social problems...[which] are often experienced subjectively as 'loss of control' [and] continues despite volitional attempts to abstain or moderate use" [22, p. 224]. The term has mostly been referred to the maladaptive dependence on a substance or a behavior. For instance, people are known to develop addictions to eating, shopping, gambling, drinking, smoking, working, and sexual behavior $[38,47]$. Analogous to the behavioral addiction, technology ${ }^{2}$-related addictions have received scholarly attention. For instance, Shotton's classic study [31] focused on computer addiction of scientists and technicians, followed by other studies examining internet addiction (e.g. [11, 47]).

In IS discipline, research on IT addiction has soared as new technologies (e.g. SNS and mobile devices) demand increasing time and attention from users [38]. This is especially evident by recent statistics pointing to an alarming rate of technology use [1]. Similar to other behavioral addictions, IT addictions were bounded to impose significant negative consequences such as reduced wellbeing and lower performance [41, 42]. Hence, recently scholars have been trying to identify the

2. It should be noted that not all technologies are equally addictive [45], prior research has shown that hedonic IT artifacts, such as SNS, are more pertinent to IT addiction than predictors of IT addictions, in an attempt to understand how to reduce or control IT addiction. For instance, prior research has highlighted the role of users' motivations and needs, habit, self-regulation, perceived enjoyment, prior use, or technology features in this regard $[33,39,41]$.

While the prior research findings have shed light on some of the antecedents of IT addiction, little attention has been devoted to the personality traits of the users who tend to exhibit addictive technology use behaviors. An exception is a recent study [42] that identified situational factors that trigger intense smartphone use for addicts such as when bored, anxious, and emotional. Nonetheless, these characteristics represent users' temporary feelings and reactions to the environment, rather than the stable personality traits, which are the focus of our study.

In contrary to such a trend in IS research, a significant body of research in general addiction literature has provided evidence showing that personality traits of individuals can play a substantial role on formation and control of substance and behavioral addictions [7]. Looking at substance addiction, several studies established the role of individuals' differences among users who have a preference for various substances (e.g. see [9, 21]). Extrapolating these findings to the context of IT addiction, we contend that specific personality traits may be associated to IT addiction behaviors (e.g. smartphone, online games, or SNS addiction). To this end, in this study, we aim to provide an overview of the key personality traits of users who show stronger symptoms of IT addiction. Rather than arbitrarily including all personality traits in this study, we follow a theory-driven approach, and draw on the FFM [6] that "theoretically capture[s] the essence of one's personality" [23, p. 810] along with the extant findings in psychology and addiction literatures to investigate the effects of three personality traits on IT addiction, namely neuroticism, conscientiousness, and agreeableness.

\section{Five-Factor Model (FFM)}

FFM has been an influential framework for theoretically understanding human's personality. The model consists of five broad personality traits namely, neuroticism, conscientiousness, agreeableness, openness to experience, and extraversion. Neuroticism refers to the extent to which a person experiences negative emotions of stress, anxiety of depression.

utilitarian IT artifacts. In this study, our notion of technology refers to such hedonic IT artifacts. 
Conscientiousness implies the ability of an individual to direct and persist at goals, and to regulate impulses. Agreeableness refers to qualities related to empathy, helpfulness, cooperativeness and having the ability to impede one's negative feelings. Openness to experience reflects the extent of being creative, unconventional and artistically sensitive, and willing to involve in an unknown experience. Finally, extraversion is the degree to which a person is social, warm, and active and is linked to elements such as assertiveness and confidence $[6,34,37]$. FFM factors represent rather-stable personality traits [23]; the generalizability and applicability of the model have been established via numerous studies, and the factors were shown to be relevant to a wide range of behaviors (e.g. see [4, 10]).

Prior research has shown that FFM can help distinguish between individuals, who show higher levels of substance addiction including alcohol, smoking and drug addiction [18]. For instance, one meta-analysis showed that high neuroticism and low conscientiousness can be correlated with substance abuse [14]. Furthermore, research on internet and communication technologies also suggested that some of FFM factors can be helpful in explaining excessive use and addiction. For instance, Ehrenberg [8] found that neurotic individuals have high tendency to use instant messaging for communication and show addictive mobile use behaviors. Also, more disagreeable individuals (who also have lower selfesteem) tend to use instant messaging more excessively. In another example, Kuss and Griffiths [16] found that conscientiousness and agreeableness are associated with problematic SNS use. Nonetheless, the evidence on the role of other two factors, namely openness to experience and extraversion, are mixed and inconclusive. For instance, based on a meta-analytic review of 12 studies on internet addiction, Kayiş, et al. [12] confirmed that "there is no relation between openness to new experiences and unhealthy internet use in some researches... some researches point out that there is a positive meaningful relation $\cdots$ [Other] researches find out that there is a negative meaningful relation" (p. 36). Similarly, while some studies hint on the positive effect of extraversion on addiction [12], others suggested the positive impact of introversion [20]. As such, in this study, we focus on three of five FFM factors, namely neuroticism, conscientiousness, and agreeableness, and propose a research model to investigate the direct and indirect effects of these three factors on IT addiction, which is consistent with findings of research on substance abuse and addiction [14].

\section{Hypotheses Development}

To better understand the personality traits related to IT addiction, we build on existing literature on IT use, IT addiction, and FFM to propose a research model (see Figure 1). First, we argue that neuroticism, conscientiousness and agreeableness directly affect the IT addiction ( $\mathrm{H} 1$ to $\mathrm{H} 3$ ). Second, we contend that neuroticism and conscientiousness also has indirect effects on IT addiction by moderating some of the direct effects (H4 and H5).

Direct effects: First, we argue that neuroticism has a positive effect on IT addiction. Prior research has mainly viewed neuroticism vis-à-vis emotional stability [8]. Neurotic individuals are seen as people who frequently and easily tend to become upset and distressed [6]. They also lack necessary skills or ability to adjust to an upsetting situation and have difficulty dealing with stress [23]. Neurotic users have been shown to spend excessive time online in order to establish a sense of belonging [3]. In addition, they have a tendency to immerse in the online world in order to cope with and relieve some of the negative feelings they frequently experience in real-life [23]. Exchanging information, seeking information, and virtual socialization also facilitate interactions without the stress of face-to-face communications that neurotic people may experience [3]. Finally, neurotic people are shown to have sub-standard coping strategies to reduce an unhealthy dependence to use of technology, which may lead to development of an addiction to the technology over time. Hence, we hypothesize that:

H1: Neuroticism has a positive direct relation with IT addiction.

Second, we contend that conscientiousness has a negative effect on IT addiction. By definition, conscientiousness refers to the ability of the individuals to plan and purposefully and persistently attempt to achieve a meaningful goal [6]. The term has also been associated with responsibility, impulse control, selfdiscipline and reliability $[6,23]$. People with high level of conscientiousness tend to have measured and controlled use of IT, which is directed at achieving a specific goal that usually helps improving their performance [29]. In the same vein, these individuals actively avoid spending time more than planned. For instance prior research has shown that conscientious people tend to spend time in the online environment on academic pursuit rather than leisure [23]. In contrast, people with low conscientiousness levels are more likely to develop an addiction to the technology, since they cannot resist the impulses that push users toward long and extended use of technology. Prior research has shown that, low conscientiousness predicts higher text and instant messaging use [8]. Accordingly, we hypothesize that: 
H2: Conscientiousness has a negative direct relation with IT addiction.

Agreeableness represents the qualities related to the sympathy, flexibility, friendliness, helpfulness, and empathy $[6,8,29]$. People with high agreeableness tend to behave cordially and cooperatively, while those with low level of agreeableness (high levels of disagreeableness) tend to use power and show aggression when dealing with a conflict or difficult situation [29]. Prior research has shown lower scores of agreeableness to be associated with drug, alcohol, and cocaine use [18].

We argue that agreeableness has direct negative effect on IT addiction. Disagreeable people tend to immerse in technologies such as internet and SNS, since there is less demand for friendly and cooperative behaviors in virtual environments as compared to reallife environments [46]. For instance, one study showed that people with low levels of agreeableness are more likely to be Wikipedia editors, since they can correct articles without having to show sympathy or cordiality toward the original authors of the articles [2]. The anonymity, limited rules, and unstructured policies of online environment can be conducive to individuals with higher tendencies toward aggressive and hostile behaviors (lower agreeableness). In the same way, such individuals may find communication using online technologies, such as SNS, easier and less challenging than face-to-face interactions. Therefore,

H3: Agreeableness has a negative direct relation with IT addiction.

Moderation effects: prior evidence on the role of personality traits suggests that the effect of each trait can possibly increase or decrease by other standing personality traits [37]. Therefore, an analysis of interaction effects might be needed to provide a more complete picture of their effects on IT addiction. To this end, we hypothesize two interaction effects that moderate the effects explained previously in $\mathrm{H} 2$ and $\mathrm{H} 3$.

First, conscientious individuals tend to behave in a logical manner where a decision is made carefully and future contingencies of an action are taken into considerations [6]. In the context of our study, this translates into a deliberate and controlled use of technology. While conscientiousness allows for high regulation over a behavior, neurotic individuals tend to show low emotional stability meaning that in situations where urge and craving exist, they show lack of resistance to such cues [37]. This is the case with regard to many social and communication technologies that provide immediate sense of enjoyment for the user. As a result, even though one might have a tendency to behave deliberately and self-regulatory in most cases, $\mathrm{s} / \mathrm{he}$ may fail to take preventive actions against urge, and eventually develop an addiction. Furthermore, neurotic individuals have been shown to follow emotion-focused coping efforts [45]. Hence, when presented by a problem or when experience some negative consequences of their technology use, they look for ways to justify their actions and reduce the negative feelings, rather than fixing the behavior. Therefore, we hypothesize that:

H4: Neuroticism negatively moderates the direct negative relation between conscientiousness and IT addiction.

Moreover, prior research on addiction contends that disagreeable individuals exhibit higher addiction levels and low tendency to go through treatment process [37]. Similar findings were reported with regard to mobile, Facebook or instant messaging service use [8]. In addition, research on personality has shown that low conscientiousness and low agreeableness can become problematic and influence person's reaction to a psychotherapy to control drug or alcohol addiction [28]. Also, in some studies, these traits were linked to poor therapy outcomes [37].

While low agreeableness may result in high IT addiction, conscientiousness could moderate this effect. Conscientious individuals tend to be attentive to details, and outcomes [34]. When a behavior - i.e. IT use causes some negative problems [42], conscientious individuals exert self-control in order to reduce the

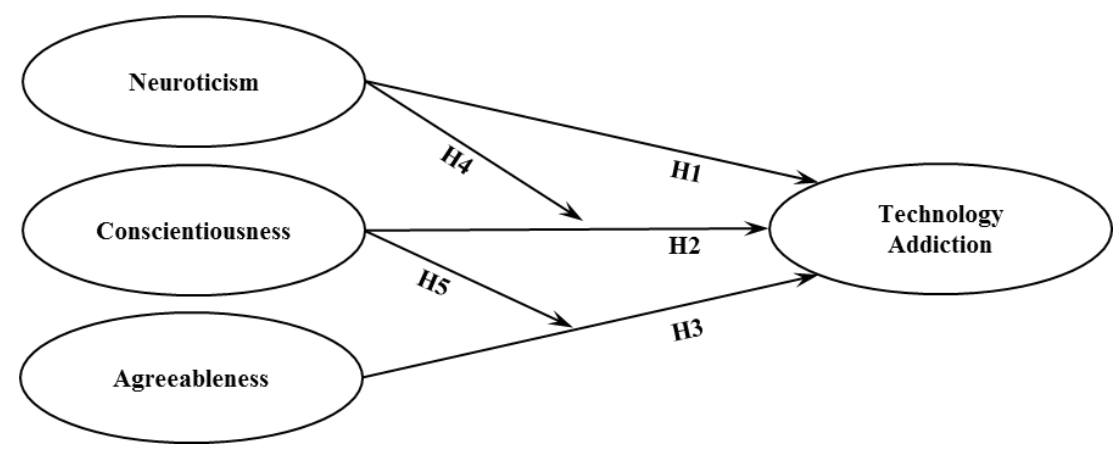

Figure 1. Research Model 
negative effect of that behavior. As Carver and ConnorSmith [6] explain, conscientious individuals tend to engage in problem-focused coping and active efforts to reduce an existing problem. Therefore, we expect that the when conscientiousness is higher, the effect of disagreeableness on IT addiction reduces. To formally hypothesize:

H5: Conscientiousness positively moderates the direct negative relation between agreeableness and IT addiction.

\section{Methodology}

\subsection{Context: Social Networking Sites (SNS)}

SNS represents web-based services that allow users to "(1) construct a public or semi-public profile within abounded system, (2) articulate a list of other users with whom they share a connection, and (3) view and traverse their list of connections and those made by others within the system" [5, p. 211]. Although the use of such networks provides known benefits, recent research and usage statistics have warned about users' addiction to SNS [39, 40]. Thus, we contend that SNS provides a relevant and appropriate context for studying IT addiction in this study.

\subsection{Procedure and Sample}

We collected the self-report data in two rounds $\left(t_{1}\right.$ : Week 1: and $t_{2}$ : Week 4) from 275 SNS users who were undergraduate and graduate students at a large North American university. The multi-wave nature $\left(t_{1}\right.$ and $\left.t_{2}\right)$ of our sample allowed us to avoid the potential effects of common method variance on our results. Furthermore, we deem this sampling choice relevant to this research because university students are more prone than others to develop addictions to SNS due to their flexible schedules and their frequent use of such sites for developing their identities [15, 40, 41, 43]. The respondents included $51 \%$ women and $49 \%$ men, and their average age was $21(18-39, \mathrm{SD}=2.64)$. They, on average, had more than 9 years of SNS experience and spent more than 90 minutes per day on its use. The survey asked students to focus on their most frequently used SNS.

\subsection{Measures}

Measurement items were adapted from wellestablished and reliable research instruments. Specifically, SNS addiction was measured at $\mathrm{t}_{2}$ using self-reported (perceived) measures used in previous addiction studies [40]. Personality traits were measured at 11 using Srivastava, et al. [34]'s scale. As explained above, in this study, we focus on neuroticism, conscientiousness, and agreeableness, as our factors of interest due to their theoretical relevance to IT addiction. Nonetheless, in the interest of comprehensiveness, we also measured other two FFM factors, namely openness to experience and extraversion. Our analysis confirmed that openness to experience and extraversion do not have a significant effect on IT addiction. As such, considering lack of strong theoretical and empirical consensus on the effects of these factors $[12,20]$, we have chosen not to include them in this paper.

\section{Data analysis and results}

\subsection{Preliminary Analyses}

A series of preliminary data analyses were performed to ensure the absence of artifacts that can compromise the results: (1) low validity of factors [35], (2) low reliability of factors [30], (3) serious deviations from normality assumption [26], and

(4)

Table 1. Descriptive statistics, correlations, and validity information

\begin{tabular}{|c|c|c|c|c|c|c|c|c|c|c|}
\hline & & $\begin{array}{l}\text { Mean } \\
\text { (S.D.) }\end{array}$ & Alpha & $\begin{array}{c}\text { Sk. } \\
\text { (Kr.) }\end{array}$ & 1 & 2 & 3 & 4 & 5 & 6 \\
\hline 1 & Addiction ( $\left.t_{2}\right)$ & $\begin{array}{c}2.75 \\
(1.15) \\
\end{array}$ & 0.90 & $\begin{array}{c}0.43 \\
(-0.44) \\
\end{array}$ & 0.76 & & & & & \\
\hline 2 & Neuroticism $\left(t_{1}\right)$ & $\begin{array}{c}3.84 \\
(1.32) \\
\end{array}$ & 0.75 & $\begin{array}{c}-0.06 \\
(-0.79) \\
\end{array}$ & 0.17 & 0.77 & & & & \\
\hline 3 & $\begin{array}{l}\text { Conscientiousness } \\
\left(t_{1}\right)\end{array}$ & $\begin{array}{c}5.36 \\
(1.27) \\
\end{array}$ & 0.75 & $\begin{array}{l}-0.94 \\
(0.98)\end{array}$ & -0.13 & -0.15 & 0.80 & & & \\
\hline 4 & Agreeableness $\left(t_{1}\right)$ & $\begin{array}{c}5.56 \\
(0.90)\end{array}$ & 0.73 & $\begin{array}{l}-0.85 \\
(2.04)\end{array}$ & -0.07 & 0.10 & 0.22 & 0.77 & & \\
\hline 5 & Age $\left(t_{1}\right)$ & $\begin{array}{l}20.94 \\
(2.64)\end{array}$ & - & $\begin{array}{c}2.95 \\
(2.12)\end{array}$ & 0.06 & -0.01 & -0.13 & 0.06 & 1.00 & \\
\hline 6 & Gender $\left(t_{1}\right)$ & $\begin{array}{c}0.50 \\
(0.50)\end{array}$ & - & $\begin{array}{c}0.04 \\
(-2.01)\end{array}$ & -0.22 & -0.14 & -0.05 & -0.07 & -0.14 & 1.00 \\
\hline
\end{tabular}




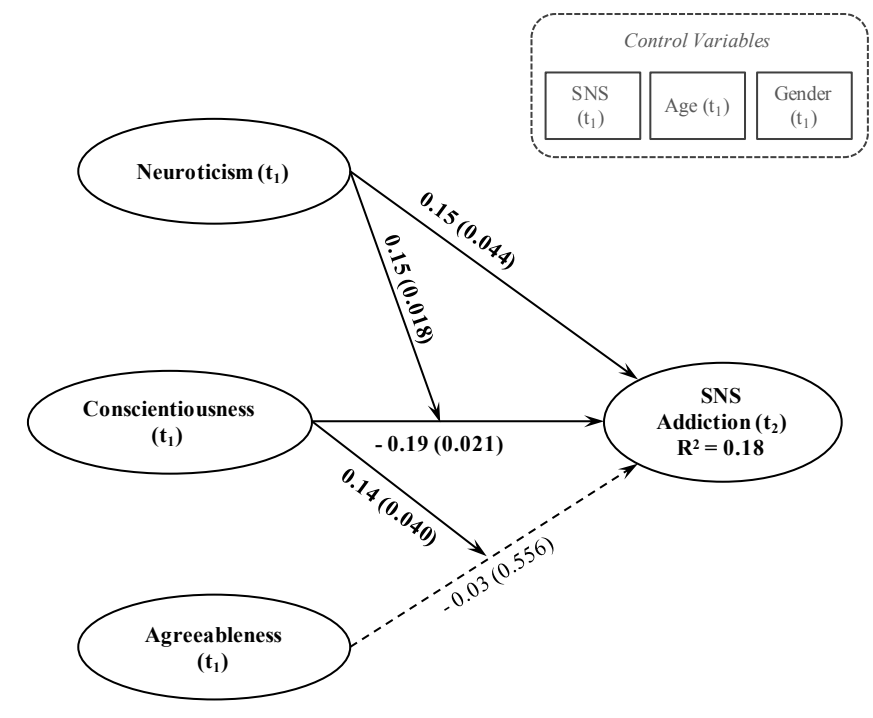

p-values are presented in parentheses.
$N=275$;
Chi-square $(178)=347.946 ;$
CFI $=0.91 ; I F I=0.91 ; T L I=0.90 ; S R M R=0.055 ;$ RMSEA $=0.059(95 \%$ Confidence Interval: $0.050-0.068)$.

Figure 2. Results of Covariance-Based SEM Analysis

multicollinearity among the factors [26]. To this end, the descriptive statistics, kurtosis and skewness indices, average variance extracted (AVE) scores, reliability scores, and inter-factor correlations were calculated for the factors, as presented in Table 1. Second, a confirmatory factor analysis (CFA) model using AMOS version 23 was estimated to ensure the goodness-of-fit of the measurement model.

The results of these analyses demonstrated that all factors were internally consistent and Cronbach's alphas scores were all above 0.7 [30] (see Table 1). Moreover, the results demonstrated good construct validity with square root of AVE scores over 0.75 , which well exceed the corresponding correlations with other factors [35]. Furthermore, the kurtosis and skewness indices were between \pm 3 , which does not indicate any serious deviation from normality $[13,26]$. Moreover, variance inflation factor (VIF) indices of less than 1.59 indicated that multicollinearity was not an issue in these data [26]. Furthermore, the CFA estimation showed that the measurement model fits the data well $(\mathrm{RMSEA}=0.059$ with $95 \%$ confidence interval of $(0.050-0.068)$; SRMR $=0.055 ; \mathrm{CFI}=0.91$; IFI $=0.91$; and TLI $=0.90)$.

\subsection{Hypotheses Testing}

The results of covariance-based structural equation modeling (CBSEM) analyses using the product terms of factor scores for the moderation relations show that the proposed research model (Figure 1) exhibits good fit to the data (RMSEA $=0.059$, with $95 \%$ confidence interval of $(0.050-0.068) ; \mathrm{SRMR}=0.055 ; \mathrm{CFI}=0.91$;
$\mathrm{IFI}=0.91$; and TLI $=0.90)$. Furthermore, estimated path coefficients and their significance levels (Figure 2) show that most of our hypotheses were supported.

Results of our CBSEM analysis supported our first hypothesis that neuroticism has a significant positive association with the SNS addiction (H1: 0.15, p = 0.044). Similarly, our second hypothesis stating that conscientiousness is significantly and negatively associated with SNS addiction was also supported (H2: $-0.19, p=0.021)$. However, our third hypothesis stating that there is a negative and significant relation between agreeableness and SNS addiction was not supported by our CBSEM analysis (H3: -0.03, $\mathrm{p}=0.556)$. Results of our CBSEM analysis supported our expectation that neuroticism negatively moderates the negative effect of conscientiousness on SNS addiction (H4: 0.15, p = 0.018). However, in contrast to our expectations, our results showed that conscientiousness negatively (rather than positively) moderates the relation between agreeableness and SNS addiction (H5: 0.14, p = 0.04). While this result indicates a significant moderation effect of conscientiousness, its valence is opposite to our expectations. Hence $\mathrm{H} 5$ is not supported. We will delve further into the moderation results via the following post-hoc analyses.

\subsection{Post-hoc Analysis (1): A Deeper Look into the Moderation Effect of Neuroticism}




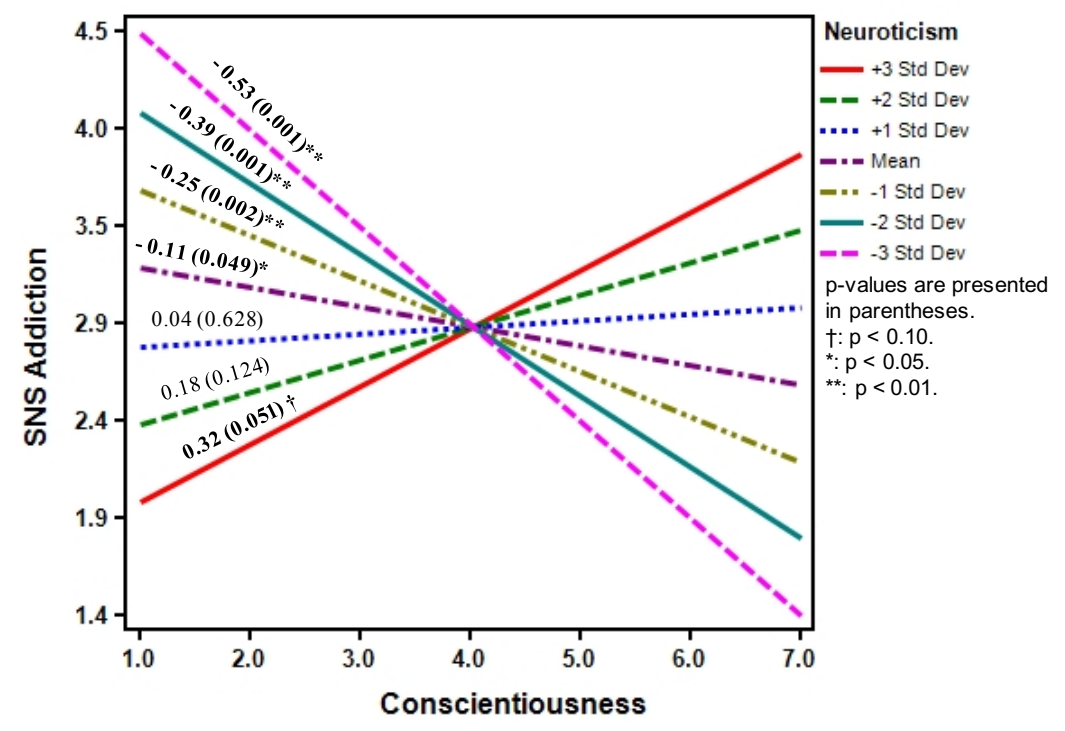

Figure 3. Post-hoc Analysis of the Moderation Effects of Neuroticism

Our CBSEM results supported our expectation that, in addition to having a positive direct effect on SNS addiction, neuroticism also negatively moderates the negative effect of conscientiousness on SNS addiction. This means that at higher levels of neuroticism, the controlling effect of conscientiousness on SNS addiction will be less effective. To better illustrate and this moderation effect, we drew on the Interaction software package [32], as depicted in Figure 3.

The plot and path coefficients presented in Figure 3 show the effect of conscientiousness on SNS addiction at different levels of neuroticism (based on the number of standard deviations above and below the mean). As such, Figure 3 shows that the effect of conscientiousness on SNS addiction is strongly negative and significant, but it diminishes as the level of neuroticism increases. Furthermore, when neuroticism is at least one standard deviations above the mean, the negative effect of conscientiousness on SNS addiction turns nonsignificant. Interestingly, when the neuroticism is at its peak (at least 3 standard deviations above the mean) the effect of conscientiousness on SNS addiction turns positive and marginally significant $(p<0.10)$. These results indicate that conscientiousness has a controlling (negative) effect on SNS addiction among the individuals with medium to low levels of neuroticism. When the level of neuroticism increases beyond the medium level, conscientiousness will lose its controlling effect, and may even contributes to SNS addiction at very high levels of neuroticism (+3 standard deviations).

\subsection{Post-hoc Analysis (2): A Deeper Look into the Moderation Effect of Conscientiousness}

Moreover, in contrast to our expectations in H5, our CBSEM results indicated that conscientiousness has a significantly negative moderation effect on the relation between agreeableness and SNS addiction. To better understand this effect, we used Interaction software package [32] as depicted in Figure 4.

As presented in Figure 4 and contrary to our expectation, the effect of agreeableness on SNS addiction will be more negative and significant, when the individual's conscientiousness is lower. In particular, when conscientiousness is at least two standard deviation below the mean (relatively low), agreeableness has a significantly negative effect on SNS addiction. This means that for individuals with relatively low conscientiousness, lower agreeableness (higher disagreeableness) is associated with higher levels of addiction to SNS. However, as the level of conscientiousness increases, the negative effect of agreeableness on SNS addiction is reduced. Interestingly, as indicated in Figure 4, at high levels of conscientiousness (at least two standard deviations above the mean) the valence of relation between agreeableness and SNS addiction marginally changes. In other words, when conscientiousness is relatively high, agreeableness has a marginally significant and positive relation with SNS addiction. We will discuss this surprising, yet interesting finding along with our other findings next.

\section{Discussions and Conclusion}

This study explains the complex relationship between personality traits in formation and control of addiction to a hedonic IT artifact. In particular, drawing 


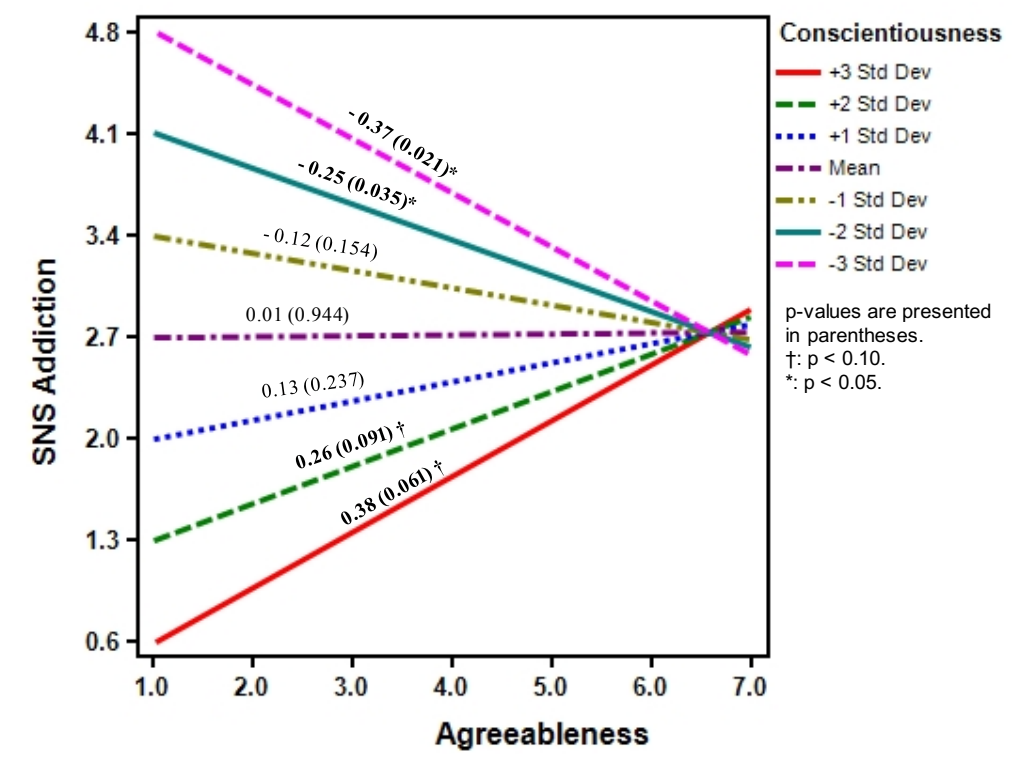

Figure 4. Post-hoc Analysis of the Moderation Effects of Conscientiousness

on FFM [10, 34], this study showed that three personality traits - neuroticism, conscientiousness, and agreeableness - directly and indirectly influence the formation and control of IT addiction. These findings have important contributions for research and practice, as follows.

While prior studies have recently looked at the direct role of personality factors on IT addiction [e.g., 12], to the best of our knowledge, this is the first study that considers the moderated effects of these personality factors on IT addiction. Our study contributes to the dark side literature by explanting the complex interactions between neuroticism, conscientiousness, and agreeableness and IT addiction. Our findings show while neuroticism is directly related to IT addiction, it also has an indirect effect on IT addiction by moderating the effect of conscientiousness on IT addiction. This implies that even though conscientiousness has a regulatory (negative) effect on IT addiction, the effect is reduced when for those who have higher levels of neuroticism. Additional analysis revealed that for the individuals with above-average levels of neuroticism in our sample, the conscientiousness loses its regulatory effect on IT addiction. This finding is unique to our study.

Furthermore, we showed that in addition to its direct negative effect, conscientiousness has an indirect effect on IT addiction by moderating the relation between agreeableness and IT addiction. While, in contrary to our expectation, agreeableness was not significantly associated with IT addiction, our findings indicate that the effect changes based on users' level of conscientiousness. Additional analyses showed that for individuals with low levels of conscientiousness (at least two standard deviations below the mean), higher levels of agreeableness (lower levels of disagreeableness) are significantly associated with lower levels of IT addiction. This finding explains that while disagreeable people are more likely to develop addiction to IT artifacts, their lower levels of conscientiousness can further increase this likelihood. However, this association is faded for the users with higher levels of conscientiousness (see Figure 4). Indeed, when conscientiousness is relatively high (at least two standard deviations above the mean), agreeableness has a marginally significant and positive relation with SNS addiction, meaning that agreeableness can, at least marginally, contribute to IT addiction.

This novel (and rather unexpected) insight could be explained from "rational addiction" perspective [17], where some addicts "anticipate the future consequences of their current behaviors and attempt to maximize utility from their intertemporal consumption choices" [17, p. 919]. With regard to personality traits, similar situation may apply to agreeable users with high empathy toward their SNS friends. Agreeable SNS users likely value their relationships with their friends on SNS. High conscientiousness for this group of users can result in spending much time communicating with their SNS friends, as a goal they would deliberately pursue. As such, higher levels of agreeableness, under high level of conscientiousness, may result in higher level of addiction to SNS. However, a unique characteristic of this type of users is that their addiction is not a result of irrationality and lack of impulse control, as is often associated with addiction [17]. Instead, they follow a rather rational process that gives way to development of 
SNS addiction [17]. These findings were contrary to our H5 and the existing literature; thus, they provide important additions to our knowledge of the complex interactions among the personality traits leading to addictions to IT artifacts. Future research can validate these findings and also test potential non-linear effects of personality factors on IT addiction.

Our findings also have implications for practitioners by enabling them to better understand the dispositional roots of IT addiction in users' personality traits and how they can be treated more effectively. Our findings explain that users with higher levels of IT addictions may not be considered as one homogeneous group of users, as different personality traits can play different roles in users' dispositions toward IT addiction. More importantly, practitioners need to pay more attention to the profile of users rather than a specific trait, since various traits may have interaction effects on each other which may increase or decrease the likelihood of developing an addition. Hence, to help such users control their IT addiction, a diversity of treatment modalities and policies might be necessary [36]. For example, users high on neuroticism scores who also suffer from IT addiction might benefit from treatments that can help them lower their neuroticism levels, which is directly associated with their IT addiction. Nonetheless, this should be considered with caution, as further research will be needed to understand how the effect of a relatively stable personality trait such as neuroticism can be effectively controlled. Moreover, as another example, the users who are low on both agreeableness and conscientiousness scores might similarly be prone to IT addiction, even though their level of neuroticism might not be necessarily as high as the users in the former example. The policies and treatments to control the IT addiction for this group of users should be commensurate with their personality profile, which can be different from the treatments deemed effective in the former example.

Important in this regard is the consideration of personality profiles of the users in understanding the roots of their disposition to IT addiction. This is important because of the interaction effects of personality traits on their effects on IT addiction and can be an important agenda for future research. In particular, future research can look into the profiles of users based on their personality traits and study how different profile of users are prone to, aware of, and willing to take action against IT addiction. This would require a personcentered view, rather than a variable-centered view to IT addiction [24, 25, 44]. Such a person-centered study can be an important contribution to both the research and practice in the IT addiction literature, and add to our knowledge of this under-studied area of research.

\section{References}

[1] "World Internet Users Statistics and 2014 World Population Stats", (2014).

[2] Y. Amichai-Hamburger, H. Kaplan and N. Dorpatcheon, "Click to the past: The impact of extroversion by users of nostalgic websites on the use of Internet social services", Computers in Human Behavior, 24 (2008), pp. 1907-1912.

[3] T. Amiel and S. L. Sargent, "Individual differences in Internet usage motives", Computers in Human Behavior, 20 (2004), pp. 711-726.

[4] M. R. Barrick and M. K. Mount, "The big five personality dimensions and job performance: a meta-analysis", Personnel psychology, 44 (1991), pp. 1-26.

[5] d. m. boyd and N. B. Ellison, "Social network sites: Definition, history, and scholarship", Journal of Computer-Mediated Communication, 13 (2008), pp. 210230.

[6] C. S. Carver and J. Connor-Smith, "Personality and coping", Annual review of psychology, 61 (2010), pp. 679-704.

[7] T. Correa, A. W. Hinsley and H. G. de Zúñiga, "Who interacts on the Web?: The intersection of users' personality and social media use", Computers in Human Behavior, 26 (2010), pp. 247-253.

[8] A. Ehrenberg, S. Juckes, K. M. White and S. P. Walsh, "Personality and self-esteem as predictors of young people's technology use", Cyberpsychology \& behavior, 11 (2008), pp. 739-741.

[9] C. Evren, B. Evren, C. Yancar and M. Erkiran, "Temperament and character model of personality profile of alcohol-and drug-dependent inpatients", Comprehensive psychiatry, 48 (2007), pp. 283-288.

[10] S. D. Gosling, P. J. Rentfrow and W. B. Swann, "A very brief measure of the Big-Five personality domains", Journal of Research in personality, 37 (2003), pp. 504528.

[11] M. Griffiths, "Internet addiction: Does it really exist", Psychology and the Internet: Intrapersonal, interpersonal and transpersonal implications (1998), pp. 61-75.

[12] A. R. Kayiş, S. A. Satici, M. F. Yilmaz, D. Şimşek, E. Ceyhan and F. Bakioğlu, "Big five-personality trait and internet addiction: A meta-analytic review", Computers in Human Behavior, 63 (2016), pp. 35-40.

[13] H.-Y. Kim, "Statistical notes for clinical researchers: assessing normal distribution (2) using skewness and kurtosis", Restorative dentistry \& endodontics, 38 (2013), pp. 52-54.

[14] R. Kotov, W. Gamez, F. Schmidt and D. Watson, Linking "big" personality traits to anxiety, depressive, and substance use disorders: A meta-analysis, American Psychological Association, 2010.

[15] D. Kuss and M. Griffiths, "Excessive online social networking: Can adolescents become addicted to Facebook", Education and Health, 29 (2011), pp. 68-71.

[16] D. J. Kuss and M. D. Griffiths, "Online social networking and addiction - a review of the psychological literature", International journal of environmental research and public health, 8 (2011), pp. 3528-3552.

[17] H. E. Kwon, H. So, S. P. Han and W. Oh, "Excessive dependence on mobile social apps: A rational addiction 
perspective", Information Systems Research, 27 (2016), pp. 919-939.

[18] N. Lackner, H.-F. Unterrainer and A. C. Neubauer, "Differences in big five personality traits between alcohol and polydrug abusers: implications for treatment in the therapeutic community", International Journal of Mental Health and Addiction, 11 (2013), pp. 682-692.

[19] L. Lapointe, C. Boudreau-Pinsonneault and I. Vaghefi, Is Smartphone usage truly smart? A qualitative investigation of IT addictive behaviors, 46th Hawaii International Conference on System Sciences (HICSS), IEEE, Hawaii, USA, 2013, pp. 1063-1072.

[20] L. Lapointe and A. Beaudry, Identifying IT User Mindsets: Acceptance, Resistance and Ambivalence, 47th Hawaii International Conference on System Sciences (HICSS), 47th Hawaii International Conference on System Sciences (HICSS), Hawaii, USA, 2014, pp. 4619-4628.

[21] O. Le Bon, P. Basiaux, E. Streel, J. Tecco, C. Hanak, M. Hansenne, M. Ansseau, I. Pelc, P. Verbanck and S. Dupont, "Personality profile and drug of choice; a multivariate analysis using Cloninger's TCI on heroin addicts, alcoholics, and a random population group", Drug and alcohol dependence, 73 (2004), pp. 175-182.

[22] G. A. Marlatt, J. S. Baer, D. M. Donovan and D. R. Kivlahan, "Addictive behaviors: Etiology and treatment", Annual review of Psychology, 39 (1988), pp. 223-252.

[23] J. C. McElroy, A. R. Hendrickson, A. M. Townsend and S. M. DeMarie, "Dispositional factors in internet use: personality versus cognitive style", MIS quarterly (2007), pp. 809-820.

[24] E. L. Merz and S. C. Roesch, "A latent profile analysis of the Five Factor Model of personality: modeling trait interactions", Personality and Individual Differences, 51 (2011), pp. 915-919.

[25] J. P. Meyer and A. J. Morin, "A person-centered approach to commitment research: Theory, research, and methodology", Journal of Organizational Behavior, 37 (2016), pp. 584-612.

[26] L. S. Meyers, G. Gamst and A. J. Guarino, Applied multivariate research: Design and interpretation, Sage Publications, Inc, Thousand Oaks, CA., 2006.

[27] D. Miller, "Stale in the saddle: CEO tenure and the match between organization and environment", Management Science, 37 (1991), pp. 34-52.

[28] L. Miller, "Predicting relapse and recovery in alcoholism and addiction: neuropsychology, personality, and cognitive style", Journal of substance abuse treatment, 8 (1991), pp. 277-291.

[29] K. Moore and J. C. McElroy, "The influence of personality on Facebook usage, wall postings, and regret", Computers in Human Behavior, 28 (2012), pp. 267-274.

[30] J. Nunnally, Psychometric Theory, McGraw-Hill, New York, 1978.

[31] M. A. Shotton, "The costs and benefits of 'computer addiction'", Behaviour \& Information Technology, 10 (1991), pp. 219-230.

[32] D. Soper, "Statistics calculators", A-priori Sample Size Calculator (2011).

[33] A. A. Soror, B. I. Hammer, Z. R. Steelman, F. D. Davis and M. M. Limayem, "Good habits gone bad: Explaining negative consequences associated with the use of mobile phones from a dual-systems perspective", Information Systems Journal (2015).

[34] S. C. Srivastava, S. Chandra and A. Shirish, "Technostress creators and job outcomes: theorising the moderating influence of personality traits", Information Systems Journal, 25 (2015), pp. 355-401.

[35] D. Straub, M.-C. Boudreau and D. Gefen, "Validation guidelines for IS positivist research", Communications of the Association for Information Systems, 13 (2004), pp. 380-427.

[36] A. Terracciano and P. T. Costa, "Smoking and the FiveFactor Model of personality", Addiction, 99 (2004), pp. 472-481.

[37] A. Terracciano, C. E. Löckenhoff, R. M. Crum, O. J. Bienvenu and P. T. Costa, "Five-Factor Model personality profiles of drug users", Bmc Psychiatry, 8 (2008), pp. 22.

[38] O. Turel, A. Serenko and P. Giles, "Integrating technology addiction and use: An empirical investigation of online auction users", MIS Quarterly, 35 (2011), pp. 1043-1062.

[39] O. Turel and A. Serenko, "The benefits and dangers of enjoyment with social networking websites", European Journal of Information Systems, 21 (2012), pp. 512-528.

[40] O. Turel, "Quitting the use of a habituated hedonic information system: a theoretical model and empirical examination of Facebook users", European Journal of Information Systems, 24 (2015), pp. 431-446.

[41] O. Turel and H. Qahri-Saremi, "Problematic Use of Social Networking Sites: Antecedents and Consequence from a Dual System Theory Perspective", Journal of Management Information Systems, 33 (2016), pp. 10871116.

[42] I. Vaghefi, L. Lapointe and C. Boudreau-Pinsonneault, "A typology of user liability to IT addiction", Information Systems Journal, 27 (2017), pp. 125-169.

[43] I. Vaghefi and H. Qahri-Saremi, From IT Addiction to Discontinued Use: A Cognitive Dissonance Perspective, Hawaii International Conference on System Sciences, IEEE, Hawaii, 2017, pp. 5650-5659.

[44] M. Wang and P. J. Hanges, "Latent class procedures: Applications to organizational research", Organizational Research Methods, 14 (2011), pp. 24-31.

[45] T. A. Wills, J. M. Sandy, A. M. Yaeger, S. D. Cleary and O. Shinar, "Coping dimensions, life stress, and adolescent substance use: A latent growth analysis", Journal of Abnormal Psychology, 110 (2001), pp. 309.

[46] K. Wilson, S. Fornasier and K. M. White, "Psychological predictors of young adults' use of social networking sites", Cyberpsychology, behavior, and social networking, 13 (2010), pp. 173-177.

[47] K. S. Young, Internet addiction: The emergence of a new clinical disorder, 1996.

[48] K. S. Young and R. C. Rogers, "The relationship between depression and Internet addiction", CyberPsychology \& Behavior, 1 (1998), pp. 25-28. 